\title{
Heterozygosity and allele frequencies of the two VNTRs (ApoB and D1S80) in Iranian population
}

\author{
Nejat Mahdieh",**, Elham Tafsiri, Morteza Karimipour*, Mohammad T. Akbari* \\ *Akbari Medical Genetic Laboratory, *Genetic Research Center, University of Welfare and Rehabilitation Sciences, Tehran, Iran
}

Genetic markers are used for identity testing and paternity analysis depends on knowing the allele frequencies in the population. Minisatellites show allelic variability in the number of repeat units. We have studied the allele frequencies and heterozygosity of two VNTRs (ApoB and D1S80) in Iranian populations. A total of 96 and 82 chromosomes were analyzed by PCR and gel electrophoresis for ApoB and D1S80 respectively. In the ApoB system, allele 37 was the most common followed by allele 35 whereas allele 23 was the most common followed by allele18 at the D1S80 locus. Observed heterozygosity was relatively low in $A p o B$ than D1S80 locus, however, no significant differences were found between observed and expected heterozygosity.

Key Words: Allele frequency, heterozygosity, ApoB, D1S80, VNTR, Iranian Population

\section{Introduction}

The human genome contains a large amount of highly repetitive DNA sequences including many variable number of tandem repeats (VNTRs). Minisatellites are the loci composed of tandemly repeated sequences between 10 and 100 base pairs (bp) ${ }^{[1]}$ and showed substantial allelic variability in the number of repeat units. The VNTR markers have been used for different applications, including linkage analysis, forensic identification, paternity testing, anthropological research and phylogenetic studies. ${ }^{[2,3]}$

One of these VNTR loci is mapped on chromosome 2 and is located $75 \mathrm{bp}$ from the second polyadenylation

signal at the 3 end of the apolipoprotein $B$ gene (ApoB) and this region consists of a tandem repeat sequence, rich in $A$ and $T{ }^{[4]}$ Higher rates of polymorphism have been found for populations of different origin and ethnicity. ${ }^{[2,5-8]}$ The ApoB protein is one of the major lowdensity proteins and plays a central role in the metabolism of serum cholesterol. This locus is highly polymorphic and until now more than 25 alleles have been reported. Since ApoB 3 is a highly polymorphic and informative marker, it is ideal to study the genetic heterogeneity among different groups in Iranian ethnics (Kurd, Lur, Persian, etc.), similar to other allelic and loci heterogeneity such as GJB2 alleles in different populations of Iran. ${ }^{[9,10]}$

The D1S80 locus is located on chromosome 1, the largest human chromosome, and the repeating sequence at D1S80 is $16 \mathrm{bp}$ in length. ${ }^{[11,12]}$ To date, 32 different alleles of D1S80 (http://www.ncbi.nlm.nih.gov/ entrez/), rangeing in size from $354 \mathrm{bp}$ to $850 \mathrm{bp}$ have been identified. Thus, 528 different allelic combinations are theoretically possible. VNTR loci can be analysed by polymerase chain reaction (PCR) amplification and high-resolution agarose or polyacrylamide gel (PAGE) or capillary electrophoresis. ${ }^{[2-8,13]}$ There have been no studies on allele frequencies of these VNTRs in the Iranian populations.

The present study was undertaken to find out the allele frequencies and heterozygosity of two VNTRs (ApoB and D1S80) locus in the Iranian populations and to com- 
pare with other Asian populations.

\section{Materials and Methods}

Blood samples were collected from 48 and 41 healthy unrelated individuals for ApoB and D1S80 respectively. Genomic DNA was extracted from peripheral blood by standard methods (salting-out technique). ${ }^{\left[{ }^{[9]}\right.} \mathrm{ApoB}$ and D1S80 locus were analyzed by PCR amplification using the primers and PCR conditions as described earlier. ${ }^{[14,15]}$ The amplified product was separated on both agarose and polyacrylamide gel electrophoresis (PAGE). Following gel electrophoresis, the gels were stained using ethidium bromide and silver staining, respectively, and the repeat sizes were determined with respect to the standard Pharmacia 100-bp commercial ladder.

Allele frequencies and heterozygosities were calculated using method described by Chakraborty. ${ }^{[16]} \mathrm{X}^{2}$ test was applied to see the association between the observed and expected heterozygosities.

\section{Result and Discussion}

Allele frequencies, observed and expected heterozygosities along with the $X^{2}$ values of the two VNTRs are shown in Table 1 . Nine ApoB and 14

Table 1: Allele frequencies of $A p o B$ and D1S80 VNTRs

\begin{tabular}{lccc}
\hline ApoB allele & Frequency & D1S80 allele & Frequency \\
\hline 29 & 0.052 & 16 & 0.049 \\
31 & 0.083 & 17 & 0.024 \\
33 & 0.073 & 18 & 0.122 \\
35 & 0.240 & 19 & 0.037 \\
37 & 0.396 & 20 & 0.037 \\
39 & 0.062 & 22 & 0.085 \\
47 & 0.021 & 23 & 0.244 \\
49 & 0.031 & 24 & 0.085 \\
51 & 0.042 & 25 & 0.061 \\
& & 28 & 0.061 \\
& & 29 & 0.049 \\
& & 30 & 0.099 \\
$\mathrm{H}(\mathrm{ob})$ & 0.646 & $30<$ & 0.049 \\
$\mathrm{H}(\mathrm{ex})$ & 0.800 & $\mathrm{H}(\mathrm{ob})$ & 0.829 \\
$\mathrm{X}^{2}$ & 0.150 & $\mathrm{X}^{2}$ & 0.866 \\
\hline
\end{tabular}

$\mathrm{H}(\mathrm{ob})$ : observed heterozygosity; $\mathrm{H}(\mathrm{ex})$ : expected heterozygosity; $\mathrm{X}^{2}$ : chisqure value
D1S80 alleles were observed. There were 31 (ApoB) and 34 (D1S80) heterozygous genotypes. The most common allele for ApoB was allele 37 and for D1S80 allele 23 which followed by allele 35 (for ApoB) and allele 18 (for D1S80). Observed heterozygosity was found to be 0.646 and 0.829 for Apob and D1S80 respectively. There was no significant differences between the observed and expected heterozygosities for both the VNTRs locus.

There are many factors that suggest high heterozygosity of VNTRs loci in Iranian population, include Iran's place on the route of the Silk Road, a history of longtime wars with foreign nations, and marked immigration from neighboring countries. On the other hand, relative ethic purity has been maintained by the natural geographic borders within Iran and by an ancient culture that encourages familiar marriages that suggest low heterozygosity. In our study, observed heterozygosity in ApoB was similar to Chinese, Malay and Indian Singaporeans, higher than Taiwanese and lower than other Asian and European populations. ${ }^{[3,16-}$ 28]

The most common alleles of D1S80 are allele 24 and 18 in the United Kingdom, USA, Canadian and Indian populations. ${ }^{[29-31]}$ Although, it is rare, but in some populations such as Alaska-Inupiaq and Alaska-Yupik (USA) other alleles may be common (18 and 31 in AlaskaInupiaq and 18 and 25 in Alaska-Yupik). ${ }^{[32,33]}$ Surprisingly, we found that alleles 23 and 18 are the most common ones.

We have also compared the number of alleles and heterozygosity for $A p o B$ in Iranian population with other world populations [Table 2]. In our study, the number of allelea are less than the other Indian and Asian populations, however, heterozygosity is similar to the Asian populations and less than the Indian populations. Comparing Iranian populations with other world populations at the ApoB locus, provides evidence for a higher genetic diversity in Africans than non Africans.

Genetic markers are used for identity testing and paternity analysis depends on knowing the allele frequencies in the population. Our preliminary results indicate that both $\mathrm{ApoB}$ and D1S80 are very polymorphic in the Iranian populations. However, there have been no stud- 
Table 2: Comparison of Iranian population with world populations ${ }^{[16,28]}$ in APOB heterozygosity

\begin{tabular}{|c|c|c|}
\hline${ }^{*}$ Population* & $\begin{array}{l}\text { No. of } \\
\text { alleles }\end{array}$ & $\begin{array}{c}\text { Observed } \\
\text { heterozygosity (\%) }\end{array}$ \\
\hline Ewondo (Cameroon) & 17 & 89.2 \\
\hline New Guinea & 4 & 67.7 \\
\hline Sotho (Africa) & 15 & 88.0 \\
\hline Tunisian & 16 & 80.0 \\
\hline Curiau (African-Brazilian) & 10 & 86.6 \\
\hline Pacoval (African-Brazilian) & 9 & 71.4 \\
\hline Dogrib (Brazil) & 5 & 65.3 \\
\hline Pehunche (Chile) & 8 & 71.7 \\
\hline Mexican & 15 & 79.4 \\
\hline American Blacks & 21 & 89.7 \\
\hline French Caucasians & 12 & 76.9 \\
\hline Serbian population & 17 & 71.0 \\
\hline Catolina (Spain) & 16 & 80.8 \\
\hline Galicia(Spain) & 17 & 77.0 \\
\hline Recanati (central Italy) & 11 & 78.8 \\
\hline Calabria (Italy) & 11 & 78.4 \\
\hline German & 11 & 74.3 \\
\hline Sweden & 13 & 77.1 \\
\hline Greek & 13 & 76.0 \\
\hline Eastern European (10 populations) & 25 & $73-8$ \\
\hline Taiwanese population & 13 & 42.0 \\
\hline Chinese Taiwanians & 9 & 68.2. \\
\hline Han Chinese & 13 & 57.5 \\
\hline North Indian Bhargavas & 17 & 69.8 \\
\hline North Indian Brahmins & 18 & 74.5 \\
\hline North Indian Chaturvedis & 18 & 72.4 \\
\hline $\begin{array}{l}\text { western and southern India } \\
\text { (Kerala, Maharashtra) }\end{array}$ & & $82-8$ \\
\hline Indian singaporeans & 13 & 67.4 \\
\hline Chinese singaporeans & 13 & 52.6 \\
\hline Malay singaporeans & 13 & 59.8 \\
\hline United Arab Emirates & 18 & 80.1 \\
\hline Iranian population & 9 & 64.6 \\
\hline
\end{tabular}

ies on differences in allele frequencies using DNA markers in Iranian populations, and since the Iranian population is consisted of different ethnic groups hence, it will be interesting to study each group separately to look for genetic diversity. Furthermore, the number of segregating alleles and higher heterozygosity in Iranian populations further support the usefulness of $A p o B$ and D1S80 for population genetic studies, linkage analysis and forensic purposes.

\section{Acknowledgements}

We are grateful of personnel of Akbari Medical Genetic Laboratory.

\section{References}

1. Jeffreys AJ, Wilson V, Thein SL. Hypervariable minisatellite regions in human DNA. Nature 1985;314:6773.

2 Destro-Bisol G, Capelli C, Belledi M. Inferring microevolutionary patterns from allele-size frequency distributions of minisatellite loci. a worldwide study of the APOB 3 hypervariable region polymorphism. Hum Biol 2000;72:733-51.

3. Chen B, Guo Z, He P, Ye P, Buresi C, Roizes G. Structure and function of alleles in the 3 end region of human apoB gene. Chin Med J (Engl) 1999;112:221-3.

4. Huang LS, Breslow JL. A unique AT-rich hypervariable minisatellite 3 to the $A p o B$ gene defines a high information restriction fragment length polymorphism. J Biol Chem 1987;262:8952-5.

5 Buresi C, Desmarais E, Vigneron S, Lamarti H, Smaoui $\mathrm{N}$, Cambien F, et al. Structural analysis of the minisatellite present at the 3 end of the human apolipoprotein $B$ gene: New definition of the alleles and evolutionary implications. Hum Mol Genet 1996;5:61-8.

6. Renges HH, Peacock R, Dunning AM, Talmud P, Humphries SE. Genetic relationship between the 3 VNTR and diallelic apolipoprotein B gene polymorphism: haplotype analysis in individuals of European and South Asian origin. Ann Hum Genet 1992;56:11-33.

7. Kravchenko SA, Malyarchuk SG, Livshits LA. A population genetics study of the allelic polymorphism in the hypervariable region of the apolipoprotein $\mathrm{B}$ gene in the population of different regions of Ukraine. Tsitology Genet 1996;30:35-41.

8. Poltl R, Luckenbach C, Reinhold J, Fimmers R, Ritter H. Comparison of German population data on the apoB-HVR locus with other Caucasian, Asian and Black populations. Forensic Sci Int 1996;80:221-7.

9. Mahdieh N, Nishimura C, Ali-Madadi K, Riazalhosseini Y, Yazdan H, Arzhangi S, et al. The Frequency of GJB2 Mutations and the $\Delta$ (GJB6-D13S1830) Deletion as a Cause of Autosomal Recessive Non-syndromic Deafness in the Kurdish Population. Clin Genet 2004;65:506-8.

10. Najmabadi H, Nishimura $C$, Kahrizi K, Riazalhosseini $Y$, Malekpour M, Daneshi A, et al. GJB2 mutations: Passage through Iran. Am J Med Genet A 2005:21;[Epub ahead of print]

11. Budowle B, Chakraborty R, Giusti AM, Eisenberg AJ, Allen RC. Analysis of The VNTR locus D1S80 by the PCR followed by high-resolution PAGE. Am J Hum Genet 1991;48:137-44.

12. Nakamura $Y$, Carlson $M$, Krapcho V, White R. Isolation and mapping of a polymorphic DNA sequence (pMCT118) on chromosome 1p(D1S80). Nucl Acid Res 1988;16:9364.

13. Gene M, Huguet E, Sanchez C, Moreno P, Corbella J, Mezquita J. Study of the Apo-B minisatellite performed by PCR in the population of Catalonian (northeast Spain). Hum Hered 1995;45:70-4.

14. Kasai $K$, Nakamura $Y$, White R. Amplification of a variable number of tandem repeat (VNTR) locus (pMCT 118) by the polymerase chain reaction (PCR) and its application to forensic science. J Foren Sci 1990;35:1196-200.

15. Boerwinkle E, Xiong WJ, Fourest E, Chan L. Rapid typing of tandemly repeated hypervariable loci by the poly- 
merase chain reaction: Application to the apolipoprotein B 3 hypervariable region. Proc Natl Acad Sci USA 1989;86:212-6.

16. Chakraborty R, Fornage M, Gueguen R, Boerwinkle E. Population genetics of hypervariable loci: Analysis of PCR based VNTR polymorphism within a population. EXS. 1991;58:127-43.

17. Khan F, Agrawal SB. Genetic variation of APOB 3 hyper variable region polymorphism among Brahmins of North India. Curr Sci 2004;86:697-701.

18. Cayres VIMV, Rasario VAC. Allele frequency distributions of six hypervariable loci (D1S80, APOB, D4S43, VW1, F13A and DYS19) in two African-Brazilian communities from the Amazon region. Genet Mol Biol 2003;26:235-40.

19. Rangel-Villalobos $H$, Rivas $F$, Torres-Rodriguez $M$, Jaloma-Cruz AR, Gallegos-Arreola MP, Lopez-Satow J, et al. Allele frequency distributions of six Amp-FLPS (D1S80, APOB, VWA, THO1, CSF1PO and HPRTB) in a Mexican population. Foren Sci Int 1999;105:125-9.

20. Das B, Ghosh A, Chauhan PS, Seshadri M. Genetic polymorphism study at four minisatellite loci (D1S80, D17S5, D19S20, and APOB) among five Indian population groups. Hum Biol 2002;74:345-61.

21. Choong ML, Koay ES, Khaw MC, Aw TC. Apolipoprotein B 5'-Ins/Del and 3'-VNTR polymorphisms in Chinese, Malay and Indian Singaporeans. Hum Hered 1999;49:31-40.

22. Luis JR, Caeiro B. Study of the ApoB 3' HVR in Galicia (NW Spain). An interpopulational analysis. Anthropol Anz 1998;56:17-24.

23. Alavantic D, Glisic S, Erceg S, Stupar M. Genetic variation at the apoB 3'hypervariable region in a Serbian population. Eur J Hum Genet 1997;5:333-5.

24. Lambropoulos AF, Frangoulides E, Kotsis A, DoziVassiliades I. Rapid typing of 4 VNTR loci, 3'ApoB, MCT118, St14 and YNZ22 by the polymerase chain re- action of a Greek sample. Cell Mol Biol (Noisy-le-grand). 1995;41:699-702.

25. Pai CY, Yang CH, Chou SL, Wei YH. Frequency distribution of hypervariable VNTRs in Apo B, HVR-Ig and COL2A1 loci in Taiwan: Forensic application. J Formos Med Assoc 1995;94:164-71.

26. Biondolillo M, Mamolini E, Manni F, Scapoli C, Lorenzetti L, Barrai I. Allele and genotype frequencies for D1S80 and 3'APOB in Recanati, Central Italy. J Foren Sci 2000;45:1080-2.

27. Pan JP, Chiang AN, Chou CY, Chan WL, Tai JJ. Polymorphisms of the apolipoprotein B 3' variable number of tandem repeats region associated with coronary artery disease in Taiwanese. J Formos Med Assoc 1998;97:233-8.

28. Verbenko DA, Pogoda TV, Spitsyn VA, Mikulich AI, Bets LV, Bebyakova NA, et al. Apolipoprotein B 30-VNTR polymorphism in Eastern European populations. Eur J Hum Genet 2003;11:444-51.

29. Mastana SS, Papiha SS. D1S80 distribution in world populations with new data from the UK and the Indian sub-continent. Ann Hum Biol 2001;28:308-18.

30. Deka R, DeCroo S, Jin L, McGarvey ST, Rothhammer F, Ferrell RE, et al. Population genetic characteristics of the D1S80 locus in seven human populations. Hum Genet 1994;94:252-8.

31. Das K, Mastana SS. Genetic variation at three VNTR loci in three tribal populations of Orissa, India. Ann Hum Biol 2003;30:237-49.

32. Scholl S, Budowle B, Radecki K, Navajo SM. Pueblo, and Sioux population data on the Loci HLA-DQA1, LDLR, GYPA, HBGG, D7S8, Gc, and D1S80. J Foren Sci 1996;41:47-51.

33. Walkinshaw M, Strickland L, Hamilton H, Denning K, Gayley T. DNA profiling in two Alaskan native populations using HLA-DQA1, PM, and D1S80 loci. J Foren Sci 1996;41:478-84. 